\title{
Stage IA Distal Bile Duct Cancer AJCC v7
}

National Cancer Institute

\section{Source}

National Cancer Institute. Stage IA Distal Bile Duct Cancer A/CC v7. NCI Thesaurus. Code C88090.

Stage IA includes: T1, N0, M0. T1: Tumor confined to the bile duct histologically. N0: No regional lymph node metastasis. M0: No distant metastasis. (from AJCC 7th Ed.) 